\title{
Silver Nanoparticles Impregnated Nanocollagen as Scaffold for Soft Tissue Repair-Synthesis, Characterization, and In vitro Investigation
}

\author{
$V_{\text {Subha }}{ }^{1}$, S Kirubanandan ${ }^{1}$, R Ilangovan ${ }^{1}$ and S Renganathan ${ }^{2}$ \\ ${ }^{1}$ National Centre for Nanoscience and Nanotechnology, University of Madras, Chennai, India \\ ${ }^{2}$ Centre for Biotechnology, Anna University, Chennai, India
}

*Corresponding authors: Subha Veeramani and Kirubanandan Shanmugam, Researchers at National Centre for Nanoscience and Nanotechnology, University of Madras, Chennai -600025, India, Email: mannargudisubha@gmail.com; ksh1005@yahoo.com

\begin{abstract}
The regeneration of soft tissue is challenging task in the medicine due to infection at the wound site. Therefore, it requires a rapid regeneration scaffold for dermis and epidermis in the soft tissue. The silver nanoparticles (AgNPs) impregnated nanocollagen has been developed for soft tissue repair. The nano-collagen contained silver nanoparticles facilitates the rapid regeneration of wounded skin, when compared to collagen microfibers. Collagen was extracted from scales of Catla fish and made into nanocollagen using a standard ultrasonic processing method. The average diameter of collagen nanofibres after sonication process was evaluated to be $500 \mathrm{~nm}$. The collagen fibres are aggregated due to hydrogen bonding between amino acids in the side chain. Size of silver nanoparticles to be impregnated into the nanocollegen varied from 180 to $210 \mathrm{~nm}$. The nanocollagen with AgNPs, were characterized using UV-Vis spectroscopy, SDS PAGE, particle size analyzer, Transmission Electron Microscopy (TEM) and Fourier Transform Infrared spectroscopy (FTIR). The UV-Visible spectroscopy investigated the genesis of spherical shaped silver nanoparticles through surface plasmon band between 250 to $300 \mathrm{~nm}$. The formation of silver nanoparticles was confirmed by wavelength of $300 \mathrm{~nm}$ under UV region. The silver nanoparticles have a good antibacterial action against wound pathogens. Nanocollagen with silver nanoparticles were subjected to MTT cytotoxicity assay under optimized concentration and in vitro wound healing assay was also performed on EA.hy926 cell lines, to evaluate efficacy of this nanomaterial scaffold for wound repair. This study confirmed that silver nanoparticles impregnated nanocollagen could be a potential wound repair biomedical scaffold.
\end{abstract}

\section{Keywords}

Collagen, Catla fish, Gymnema sylvestre, MTT cytotoxicity assay, Wound healing assay

\section{Graphical Abstract}

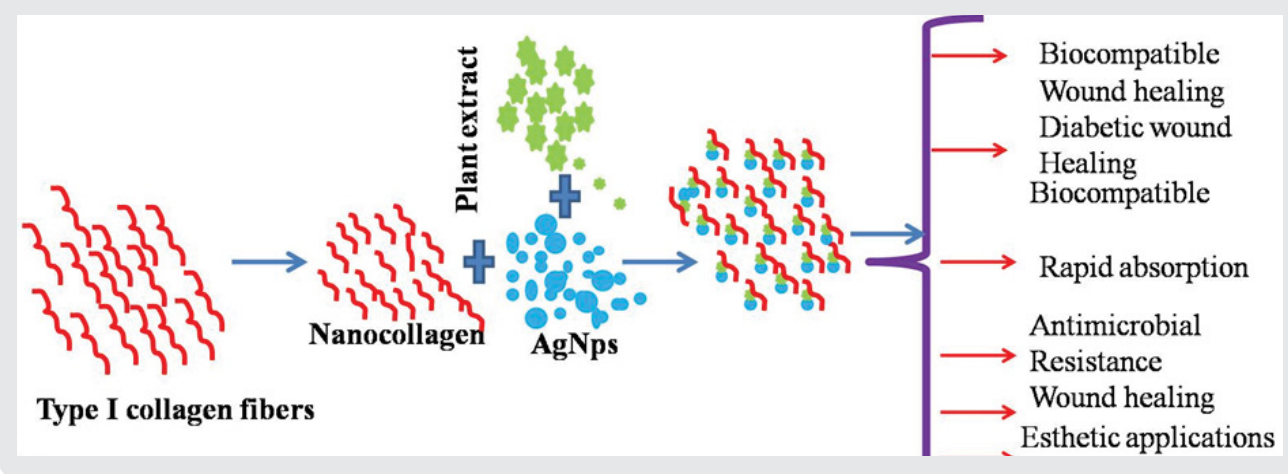

Citation: Subha V, Kirubanandan S, Ilangovan R, Renganathan S (2021) Silver Nanoparticles Impregnated Nanocollagen as Scaffold for Soft Tissue Repair-Synthesis, Characterization, and In vitro Investigation. Int J Med Nano Res 8:034. doi.org/10.23937/2378-3664.1410034

Accepted: July 07, 2021: Published: July 09, 2021

Copyright: (C) 2021 Subha V, et al. This is an open-access article distributed under the terms of the Creative Commons Attribution License, which permits unrestricted use, distribution, and reproduction in any medium, provided the original author and source are credited. 


\section{Introduction}

An effective scaffold is required for fast wound healing process. Recently, the collagen biomaterial was played as a predominant biomaterial for wound regeneration and provided enhanced the rate of healing of tissues with minimal scar formation at the wound site and excellent quality restoration of soft tissues [1]. Type 1 collagen acts as an efficient matrix for cultivating endothelial cells through in vitro methods and inducing a collection of platelets, improving blood clotting process and simultaneously speed up the wound repair process through the cellular processes. In addition, the nanofibrous nature of Type 1 Collagen provides a good extracellular matrix (ECM) protein substrate for growing stem cells for engineering various tissues [2]. Triple helix nature of the Type 1 Collagen mainly contributes to binding of various biomolecules/ biologicals substance namely membrane, growth factors and various components of ECM. Therefore, developing scaffold from Type 1 Collagen is highly considered for tailoring/augmenting/regenerating for tissue engineering practice $[1,2]$. Collagen is a fibrous protein and vulnerable to biodegradation by Staphylococcus aureus-MRSA (Methicillin-resistant) and Pseudomonas aeruginosa pathogens, which are infecting wounds and expressing proteases for enfeebling the extracellular matrix at the wound site. Hence, it is essential to include the antimicrobial agents into the collagen material to progress the functionality such as resistive scaffold to microbial dilapidation and antimicrobial scaffold for infected wounds [3].

Antimicrobial resistance created by wound pathogens is the regular clinical problem. Metallic nanoparticle is having a notable antimicrobial potential and the potential is an alternative for chemical based antimicrobial agents to incorporate with collagen. Silver nanoparticles are leading metal nanoparticles for the biomedical applications. It has wide spectrum of antimicrobial potential against various microorganism and pathogens. The advantages of silver nanoparticles in biomedical applications are effective in protracted therapeutics, good bacteriostatic and, bactericide against microorganism, good biocompatibility and low toxicity against cells at in vivo $[4,5]$.

Recently, the toxic compounds have been avoided for preparation of silver nanoparticles (AgNP). The metal-based nanoparticles attract consumer owing to its antimicrobial potential, health-related and Industry. Some of the passivating and reducing chemical agents introduced yet another challenge of high cost and toxicity. Therefore there are some limitations in using such noble materials for the biological applications. These challenges can be overcome by using 'green synthesis of metal nanoparticles. The secondary metabolites in the plant extracts are eco-friendly abundant chemical, biodegradable and non-toxic in nature into synthetic chemistry and synthesis of nanomaterials $[6,7]$. These methods of synthesis of nanomaterials are eco-friendly, renewable, and biodegradable [8]. The metallic nanoparticles were produced by plants extract are more stable when compared with the nanoparticles from other methods. The rate of formation or synthesizing nanoparticles via plant extract is fastere than other methods [9].

Recently, the silver nanoparticles impregenated collagen/chitosan composite scaffold showed that the wound healing improved via the migration of fibroblast and promoting expression of $\alpha$-smooth muscle actin. The composite gives minimal scar formed tissue and similar to normal skin. This composite provides anti bacterial action against wound pathogens due to the presence of nanosilver particles in the composite, antiinflammatory and wound healing activity [10]. However nanocollagen was not used and their effect on the wound healing was not investigated.

The present investigation deals the impregnation of silver nanoparticles with the nanocollagen for development of wound regeneration scaffold. Further, the fabricated scaffold was performed their characterization and evaluation via cell culture.

\section{Material and Methods}

\section{UV-Visible spectroscopy}

The formation of silver nanoparticles was confirmed by UV spectrophotometer is operated in the range between 200 to $400 \mathrm{~nm}$ in UV Region.

\section{FTIR analysis}

The presence of biomolecules in the stem extract was explored by FTIR analysis. The biomolecules or secondary metabolites in the stem extract play as reducing agent for forming/reduction into silver nanoparticles. The silver nanoparticles from the solution mixture was centrifuged and then dried. The dried sample was grounded with analytical reagent (AR) grade of potassium bromide to prepare the pellets for FTIR analysis. The FTIR analysis was carried using Spectrum RX-1Perkin Elmer 5.2.1 model in the range of $4000-400 \mathrm{~cm}^{-1}$.

\section{SEM and TEM investigation}

Morphological studies is the one of important characteristics and morphology of Ag NPs was studied by scanning electron microscopy (SEM), S3400N (Hitachi) model. TEM analysis was carried out using TEM Hitachi model.

\section{Investigation of collagen fibres}

Collagen and silver nanoparticles were placed on the carbon tap with copper grid, dehydrated in a standard laboratory atmosphere. Dehydrate materials placed on carbon tape was coated with a metallic layer as a 
conductive medium using sputtering technique. The conducting layer enhances the electrons on the dried collagen surface on the silicon chip. The surface of the collagen impregnated with silver nanoparticles was investigated with secondary electron mode of the SEM. The voltage used for investigating the surface was $5 \mathrm{KV}$. The SEM micrographs were captured at $5 \mu \mathrm{m}$ and 10 $\mu \mathrm{m}$.

\section{Evaluation of diameter distribution of Type 1 collagen fibres}

The size distribution of the collagen fibres were measured using the SEM micrograph images. The measurement gives average diameter of Type 1 Collagen fibres through descriptive statistics in MS EXCEL. With a support of this statistical analysis, the mean diameter was reported with $95 \%$ confidence interval.

\section{Green synthesis of silver nanoparticles}

The methanolic extract was prepared by mixing AR grade of methanol with powdered the stems of Gymnema sylvestre. This extract was played as a feed stock for green synthesis of silver nanoparticles with silver nitrate solution. The silver nanoparticle was prepared by $5 \mathrm{ml}$ of methanolic stem extract adding with $100 \mathrm{ml}$ of $1 \mathrm{mM}$ of silver nitrate solution and mixed well in shaker. The reaction mixture was incubated and allowed to chemical reaction between silver nitrate and secondary metabolites in the extract. The silver nanoparticles were formed by the reduction of silver nitrate through an observation of colour change from colourless to reddish brown in the solution. The resultant solution was centrifuged at 10000 RPM for 15 minutes to collect the silver nanoparticles. The colour change from colourless solution to reddish brown colour was observed. It confirms that the genesis of AgNPs were observed on incubation with the methonolic stem extract of Gymnema sylvestre. The Figure S1 in the supplementary information shows the protocol for green synthesis of silver nanoparticles.

\section{Extraction of Type 1 collagen from fish scales}

$0.05 \mathrm{M}$ Tris $\mathrm{HCl}$ and $20 \mathrm{mM}$ EDTA ( $\mathrm{pH} 7.5$ ) for 48 hours. The fish scales were demineralised after treating with EDTA (0.5 M-pH 7.4) till $48 \mathrm{~h}$. The demineralised scales were washed using distilled water, then $0.5 \mathrm{M}$ acetic acid $(\mathrm{pH} 2.5)$ treated for $48 \mathrm{~h}$. Then the insoluble parts of the fish scales were filtered out. The filtrate solution was treated for $24 \mathrm{~h}$ with $0.9 \mathrm{M} \mathrm{NaCl}$. The solution was centrifuged $(8000 \mathrm{rpm})$ for $1 \mathrm{~h}$ and resuspended the pellet using acetic acid with $0.5 \mathrm{M}$ concentration. This final solution was dialyzed in acetic acid ( $0.1 \mathrm{M})$ for $24 \mathrm{~h}$. It was again dialyzed against distilled water for $24 \mathrm{~h}$ and then lyophilized. Extracted collagen procedure shown in Figure S2 and extracted collagen shown in Figure S1 for impregenation of silver nanoparticles in Supplementary information.

\section{Preparation of collagen based silver nanoparticles}

$\mathrm{AgNO}_{3}$ solution $(108 \mu \mathrm{g} / \mathrm{ml})$ and type 1 nanocollagen $(0.3 \mathrm{mg} / \mathrm{ml})$ were added in same volume in beaker and kept the solution under agitation for 10 minutes. The aqueous stem extract of Gymnema sylvestre was added in the ratio of 1:6 (Ag: Reducing agent) as a reducing agent and again it was stirred for 10 minutes. Immediately after complete mixing the solution have been isolated within 15 minutes (3600 rpm) and prepared in the form of pellet after the filtration. The collagen based silver nanoparticles was analysed by UVVisible spectrophotometer. Presence of biomolecules was confirmed by FTIR spectrometer and morphology of collagen based silver nanoparticles was observed by Scanning Electron Microscope (SEM) imaging of ZEISS instrument. Synthesized silver nanoparticles shown in figure 6 in supplementary information and silver nanoparticles synthesis protocols shown in figure 2 in supplementary information.

\section{Biological evaluation of silver nanoparticles impregnated collagen cell passaging}

The analysis was performed on Human Umblical Vein Endothelial Cells (HUVEC) EA.hy926. Completely grown endothelial cell flask was gifted by neighbouring culture lab, Anna University MIT campus, Chennai. Analytical grade chemicals (HIMEDIA) have been employed in this study. Cells have been resuspended with $1 \mathrm{ml}$ of PBS (1X) and gently tapped followed by addition of 1 $\mathrm{ml}$ of Trypsin Phosphate Versene Glucose (1X). After the centrifugation trypsin was discarded and finally cell flask was incubated in $\mathrm{CO}_{2}$ incubator for 5 minutes. Finally detached cells were analysed. Thereafter culture media ( $1 \mathrm{ml}$ ) have been mixed and blended well.

\section{Cell counting}

Neubauer chamber was used to calculate number of cells present in the cell culture. $10 \mu \mathrm{l}$ of cells from culture flask was added to $10 \mu$ Tryphan blue dye, then added fine blend. $10 \mu$ of test sample was used from mixed sample and loaded in between the cover slips and also chamber. Whole set up observed by the microscope and then cells have been counted with the given formula:

No of cells in $1 \mathrm{ml}=$ Total no of cells in 16 small squares $\times 2$ (dilution factor) $\times 10^{4}$

\section{Cytotoxicity assay}

These cells have been seeded in 96 well cell culture plates. It was maintained under $37{ }^{\circ} \mathrm{C}$ for $24 \mathrm{~h}$ at $\mathrm{CO}_{2}$ incubator. Collagen based silver nanoparticles stock solution was prepared $(5 \mathrm{mg} / \mathrm{ml})$. Then the stock solution was used to prepare 11 different concentrations of samples using serial dilution method $(1000,500,100,50$, $10,5,1 \mu \mathrm{g} / \mathrm{ml}$ and $500,100,50,10 \mathrm{ng} / \mathrm{ml})$. The different concentration solutions were taken in appropriate 
wells and maintained at $37^{\circ} \mathrm{C}$ and kept it for $24 \mathrm{~h}$. The next day $10 \mu \mathrm{l}$ of MTT [3-(4,5-Dimethylthiazol-2-yl)-2, 5 -Diphenyltetrazolium Bromide] reagent $(5 \mathrm{mg} / \mathrm{ml})$ was taken in each well. Then incubate this solution for $4 \mathrm{~h}$ in $\mathrm{CO}_{2} \mathrm{~atm}$. The media was removed after incubation and DMSO $(100 \mu \mathrm{l})$ was mixed with solution. The absorbance at $540 \mathrm{~nm}$ was noted and the live cell percentage were measured using the below formula.

$$
\text { Cell viability }(\%)=\frac{\text { OD of Treated }}{\text { OD of Control }} \times 100 \ldots
$$

\section{In vitro wound healing assay}

The cells have been sowed in 24 well cell culture plates and kept warm $\left(37^{\circ} \mathrm{C}\right)$ in incubator for $24 \mathrm{~h}$ under $\mathrm{CO}_{2}$ atm. The monolayer cell culture was scraped using sterile $200 \mu \mathrm{l}$ micropipette tip to create uniform scratch. The media was separated out and media containing collagen based silver nanoparticles were added to appropriate wells. Closure of wound was observed using microscope at different intervals.

\section{Result and Discussion}

Presently, the management of dermal wound requires a considerable biological environment for tissue regeneration rapidly and activate cell fate process effectively. An infected wound surface provides a platform for the growth of wound pathogens forming a moist surface and the degraded proteins from wound surface acting as a nutrition for the growth of wound pathogens $[2,3]$. The regeneration of wound bed from microbial infection and degradation was carried out by combating the wound pathogens via drug delivery to the wound surface and this enables faster regneratation of dermis and epidermis at the infected wound site
[4]. Recently, chemical based antimicrobials and other potential agents could accelerate the wound healing process either controlling the rate of wound infection or involving in wound healing process through various biological mechanisms [5,6]. Generally, Silver based compounds has a potential antimicrobial action against both gram negative and gram positive bacteria [7]. In addition to that, Pure silver or their compounds posses potential broad spectrum antimicrobial agents and antiinflammatory properties [9]. Silver at nanoscale level possess significantly larger surface area to volume ratio, resulting good antimicrobial activity and subsequently enhance wound healing efficacy $[11,12]$. The mechanism of antimicrobial activity of silver nanoparticles was strong interaction between cationic silver nanoparticles and negatively charged surfaces of bacterial cells which are responsible for the local disruption of the inner membrane in cell wall $[13,14]$. The criteria for good wound dressing is the considerable rate of release of drug with ease mechanism of release. Burst release is very important in the design of wound dressing. This release immediately controls the infection at the wound site [15]. The other properties of silver nanoparticles and type 1 extracted collagen from fish scale have been added into the supplementary information.

\section{UV visible spectrometry analysis}

Furthermore, collagen-based dressing has found to accelerate fibroblast production and establish woundhealing process, observed that collagen extracted from the Catla fish scales showed distinct peak at $233 \mathrm{~nm}$. Also this type of collagen shows a peak near $240 \mathrm{~nm}$. The absorption of UV in the Collagen samples due to aromatic residues such as tyrosine and phenylalanine. UV spectrograph of collagen based silver nanoparticles

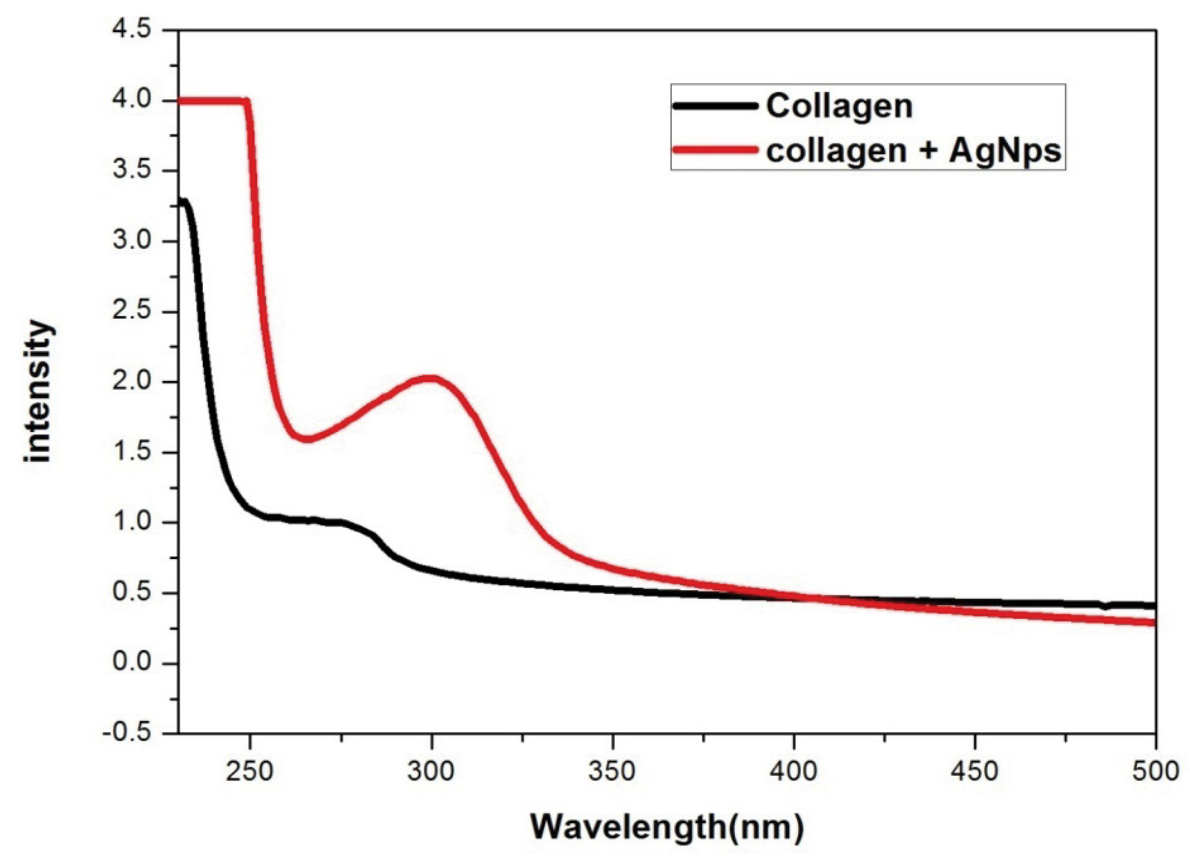

Figure 1: UV visible spectrum of collagen and nanosilver blended with collagen. 
was characterized and denoted in Figure 1. They reported that plasmon band between 380 to 450 $\mathrm{nm}$ is an indicative measure of the spherical shape of silver nanoparticles formed. This wider plasmon band is believed to be because of the aggregation of $\mathrm{Ag}$ nanoparticles. The synthesized collagen stabilized silver nanoparticles were sonicated for 20 minutes with $20 \mathrm{kHz}$ using ultrasonic processor. This sonicated nanocollagen based silver nanoparticles observed by UV light at 451 $\mathrm{nm}$, which showed the formation of nanocollagen.

\section{FTIR analysis of collagen}

FTIR analysis was carried out for collagen and silver nanoparticles to confirm their interaction. Figure 2 -FTIR spectra of pure plant extract. The Figure $3 a$ and Figure $3 \mathrm{~b}$ show FTIR spectra of type 1 collagen and silver nanoparticles impregnated collagen. The vibrational bands of the Type 1 collagen are evaluated in Figure 3a. It is found to be 1454, 1404, 1334, 1282, 1240, and 1205 $\mathrm{cm}^{-1}$ for attributing $\mathrm{CH}_{2} \mathrm{CH}_{3}, \mathrm{C}-\mathrm{N}$ and $(\mathrm{N}-\mathrm{H})$ respectively. The value of $1649 \mathrm{~cm}^{-1}$ contributes the amide 1 band mostly in the type 1 collagen. The peak was formed due to the stretching vibrations of carbonyl " $\mathrm{C}=\mathrm{O}$ " group in the pepdide bond of the collagen strand. The value of $1550 \mathrm{~cm}^{-1}$ mentions the amide II band and peak due to $\mathrm{N}-\mathrm{H}$ bending and $\mathrm{C}-\mathrm{N}$ Stretching vibrations.

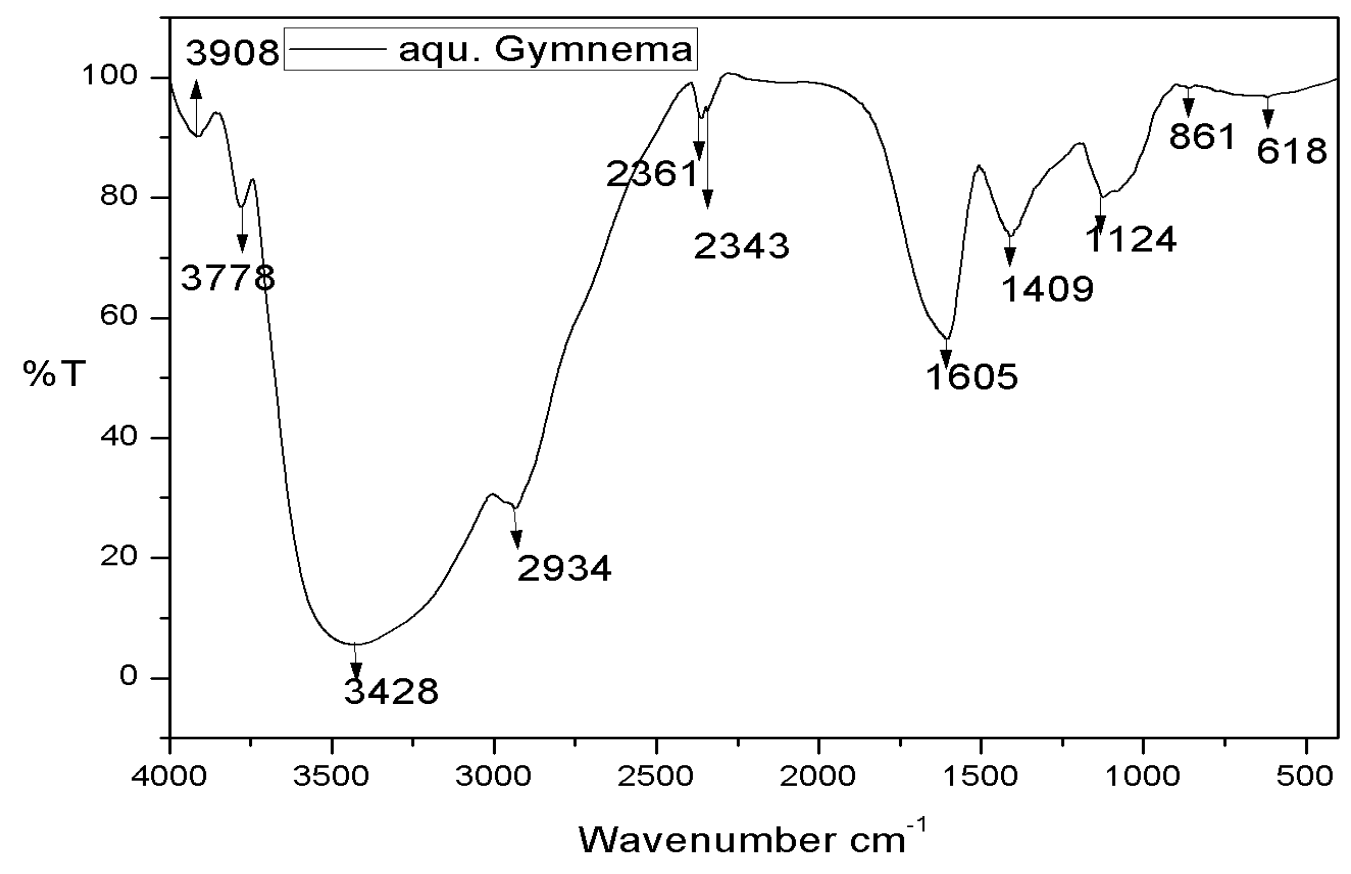

Figure 2: FTIR images of plant aquous extract.

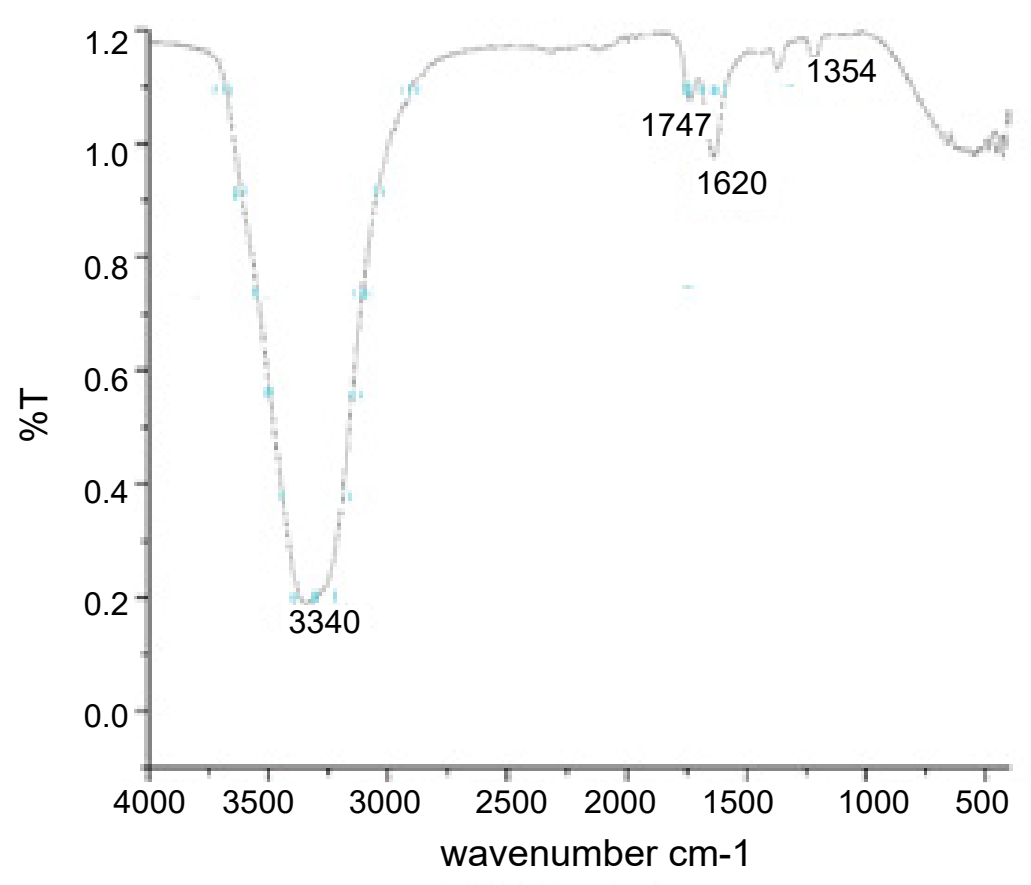

Figure 3a: FTIR image of collagen extracted from scales of Catla catla. 
Figure 3a shows the signal between 1700-1600 $\mathrm{cm}^{-1}$ in the spectrum of Type 1 Collagen confirming the conjugation of Silver nanoparticles with type 1 collagen fibres.

The analysis of functional groups interacting with nanoparticles and the stem extract of Gymnema sylvestre was performed by FTIR, shown in Figure 2. The secondary metabolites present in the plant extract reduce the silver ions into silver nanoparticles. In addition to that, the secondary metabolites can be played as capping agents for synthesis of nanoparticles. Various secondary metabolites are alkaloids, flavonoids, terpenoids, amino acids, glycosides and so forth. Peaks near $3852 \mathrm{~cm}^{-1}$ corresponds to $\mathrm{O}-\mathrm{H}$ stretch [16], peaks near $2925 \mathrm{~cm}^{-1}$ corresponds to $\mathrm{C}-\mathrm{H}$ stretch [14], peaks near $1107 \mathrm{~cm}^{-1}$ belongs to peak corresponds to functional group of aliphatic amines [17]. $2850 \mathrm{~cm}^{-1}$ to alkenes [14]. $1200-1000 \mathrm{~cm}^{-1}$ region corresponds to $\mathrm{C}-\mathrm{OH}$ side groups and the $\mathrm{C}-\mathrm{O}-\mathrm{C}$ glycosidic band vibration [10] peaks near $1107 \mathrm{~cm}^{-1}$ corresponds to $\mathrm{C}-\mathrm{H}$ stretch, peaks near 531 $\mathrm{cm}$ corresponds to alkyl halides, peaks near $1408 \mathrm{~cm}^{-1}$ corresponds to aromatic stretch [17], peaks near 1053 $\mathrm{cm}^{-1}$ corresponds to $\mathrm{C}-\mathrm{C}$ stretch, peaks near $668 \mathrm{~cm}^{-1}$ corresponds to $\mathrm{C}-\mathrm{H}$ stretch. 1636 corresponds to $\mathrm{C}=\mathrm{O}$ bond of amide [16]. These results confirmed that the silver ions reduced into silver nanoparticles through the phytochemicals like, polyphenols, terpenoids, saponins and gymnemagenin derivatives of gymnemic acid [2]. It is concluded that the nanocapping of the secondary metabolites derived from Gymnema sylvestre stem extract is the most common reason for the reduction and stabilization of the AgNPs. Table S1 at Supplementary information gives the wavelengths of various functional groups in the collagen and silver nanoparticles.

\section{Morphological analysis}

SEM micrograph shown (Figure 4), the morphology of ultrasonicated nanocollagen developed from fish scales. In SEM micrographs, the diameter of collagen fibers are measured around $500 \mathrm{~nm}$ and increased due to the aggregation of fibers. Accumulation of collagen fibers caused by hydrogen bonds between side chains of the amino acids in the collagen strands in Type 1 collagen. In Figure 4a, images show the AgNps synthesized from green synthesis. The biotransformed $\mathrm{AgNps}$ size is found to be $\sim 100-150 \mathrm{~nm}$. The AgNPs from green synthesis are heterogeneous nature in size. Collagen AgNPs was analysed by TEM analysis, in was clearly observed in Figure $4 \mathrm{~b}$ images and the nanocollagen stabilized silver nanoparticles $180-210 \mathrm{~nm}$. Figure S3 in the supplementary data show the size distribution of AgNps and found that the size of the particles varied from 100$200 \mathrm{~nm}$ and average size of AgNPs was evaluated to be $274 \mathrm{~nm}$. The spherical structure of AgNps was confirmed using from the SEM results. The collagen blended silver nanoparticles have found the brown surface with nanosilver in which collagen surrounded by synergic goodness of phytochemical extract (Figure 5).

The interactions of silver Nanoparticles with side chains of Type 1 Collagen fibers remain obscure in the

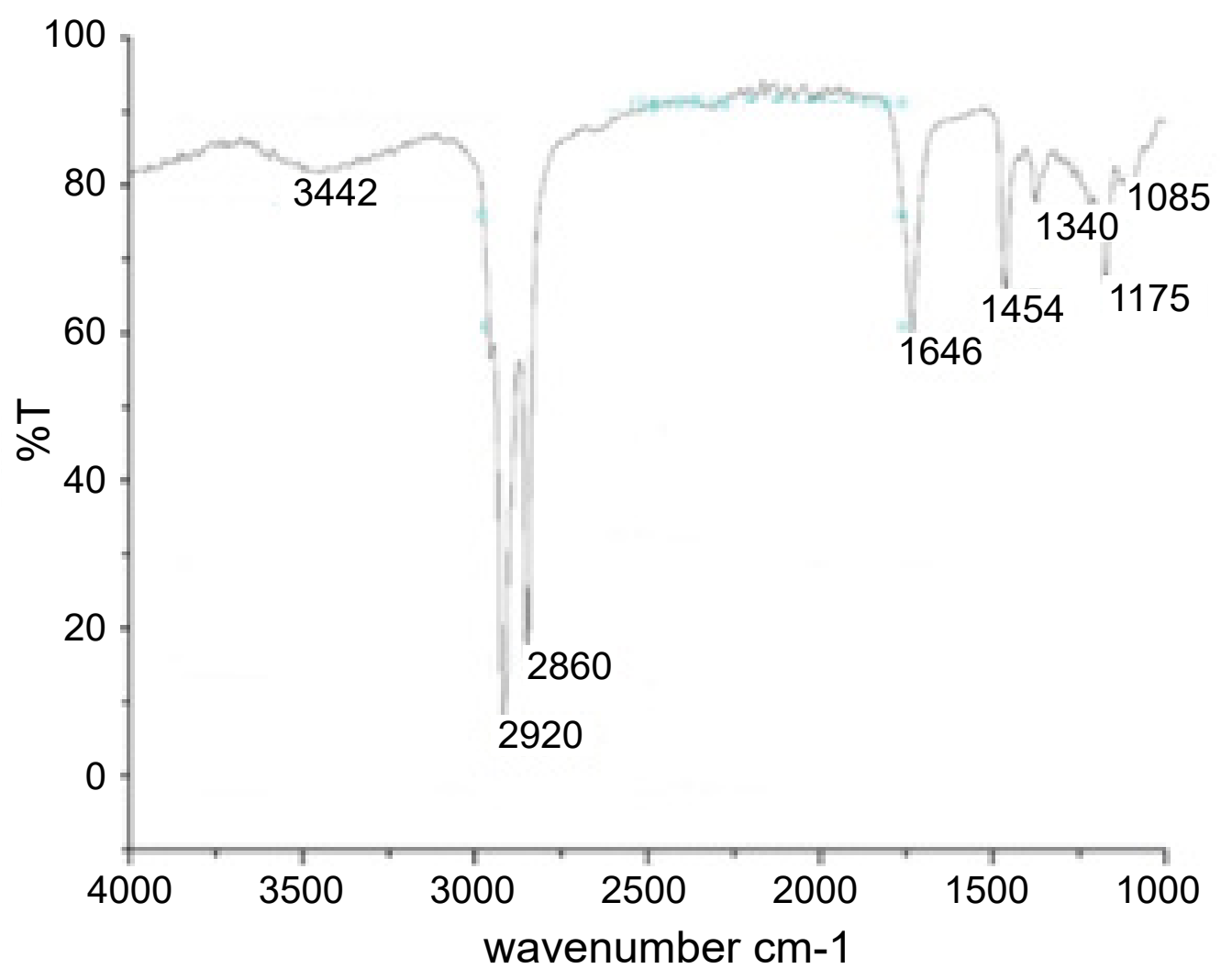

Figure 3b: FTIR images of silver nanoparticles impreganted collagen. 

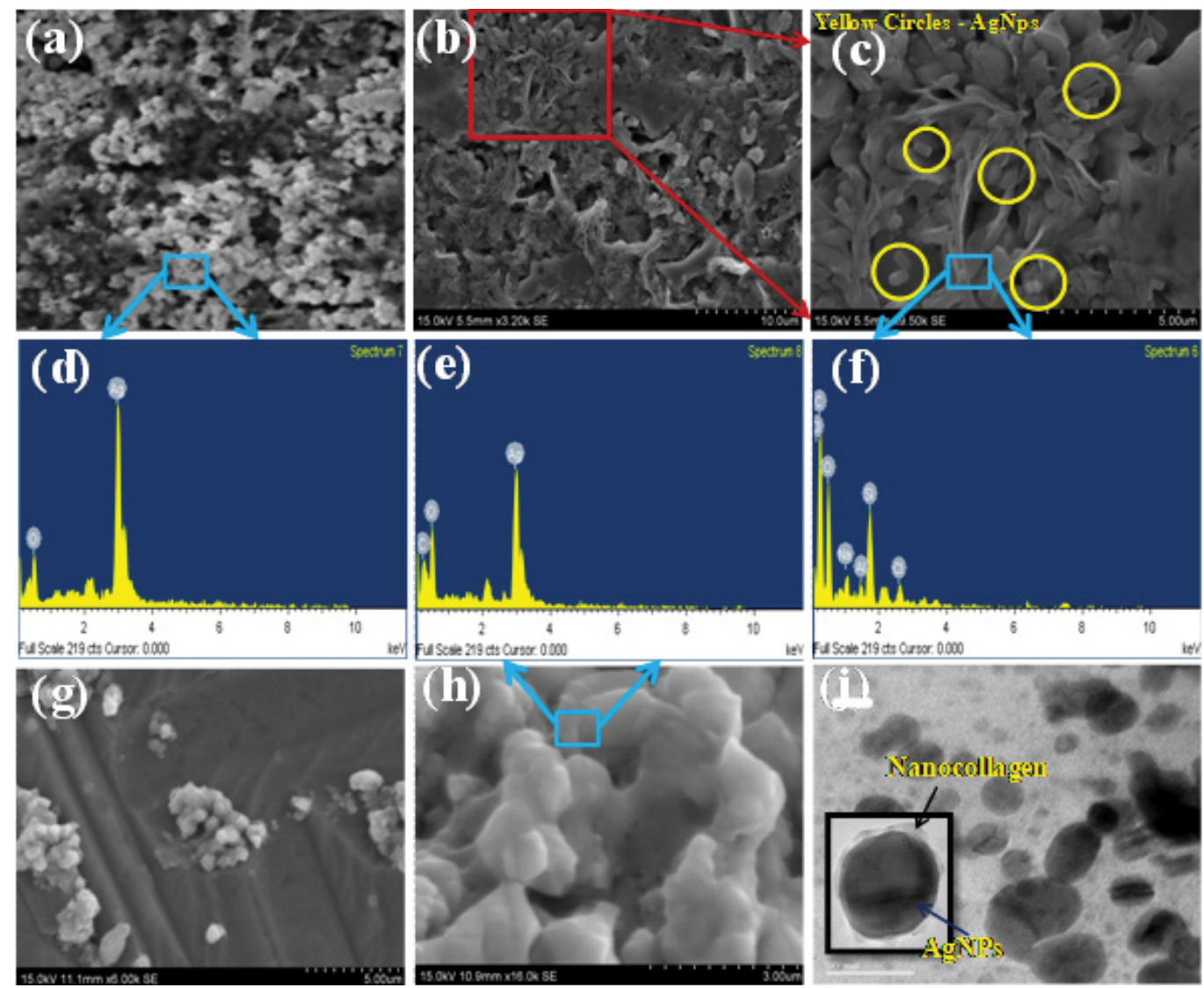

Figure 4: (a) SEM image of Silver nanoparticle extracted from plant extract, (b) AgNps blended fish collagen extracted from scales of catla catla, (c) Magnification images of silver nanoparticles impreganted collagen, (d) Elemental mappin of AgNps, (e) Elemental mapping of collagen, (f) Elemental mapping of collagen blended AgNps, (g) Nanocollagen with AgNps, (h) Higher Magnification of AgNps blended nanocollagen, (i) TEM image of collagen with silver nanoparticles.

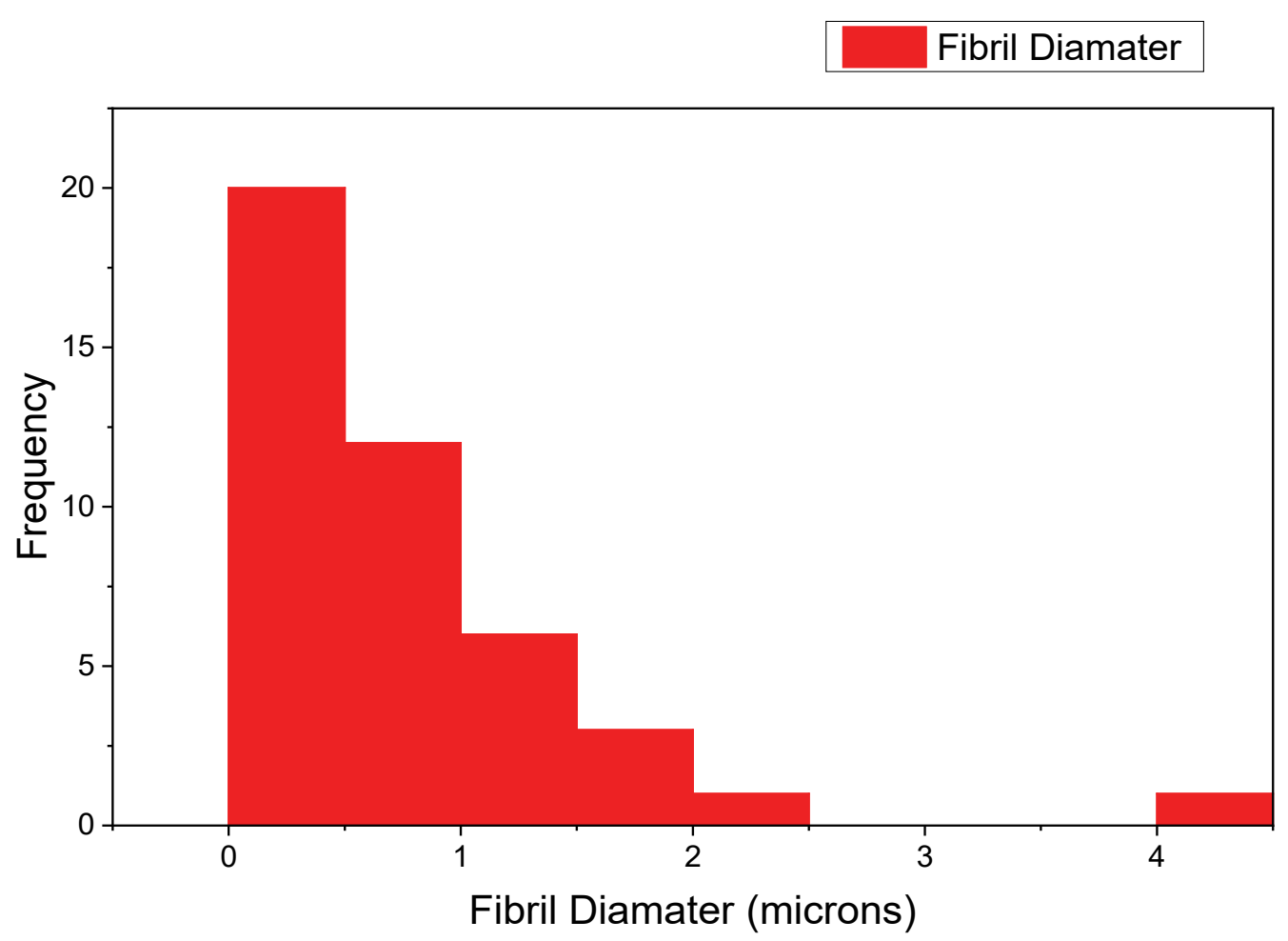

Figure 5: Histogram of AgNps blended nanocollagen. 


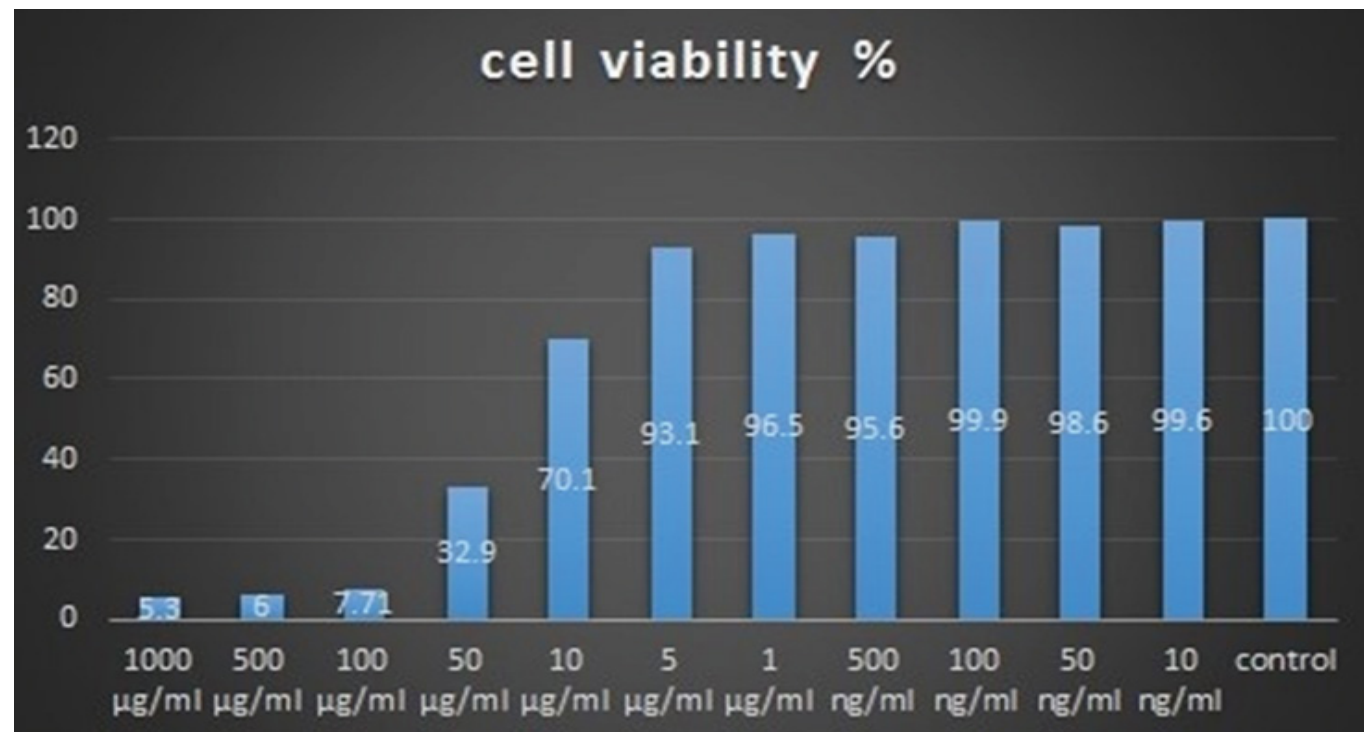

Figure 6: Cytotoxicity assay of nanocollagen stabilized silver nanoparticles.

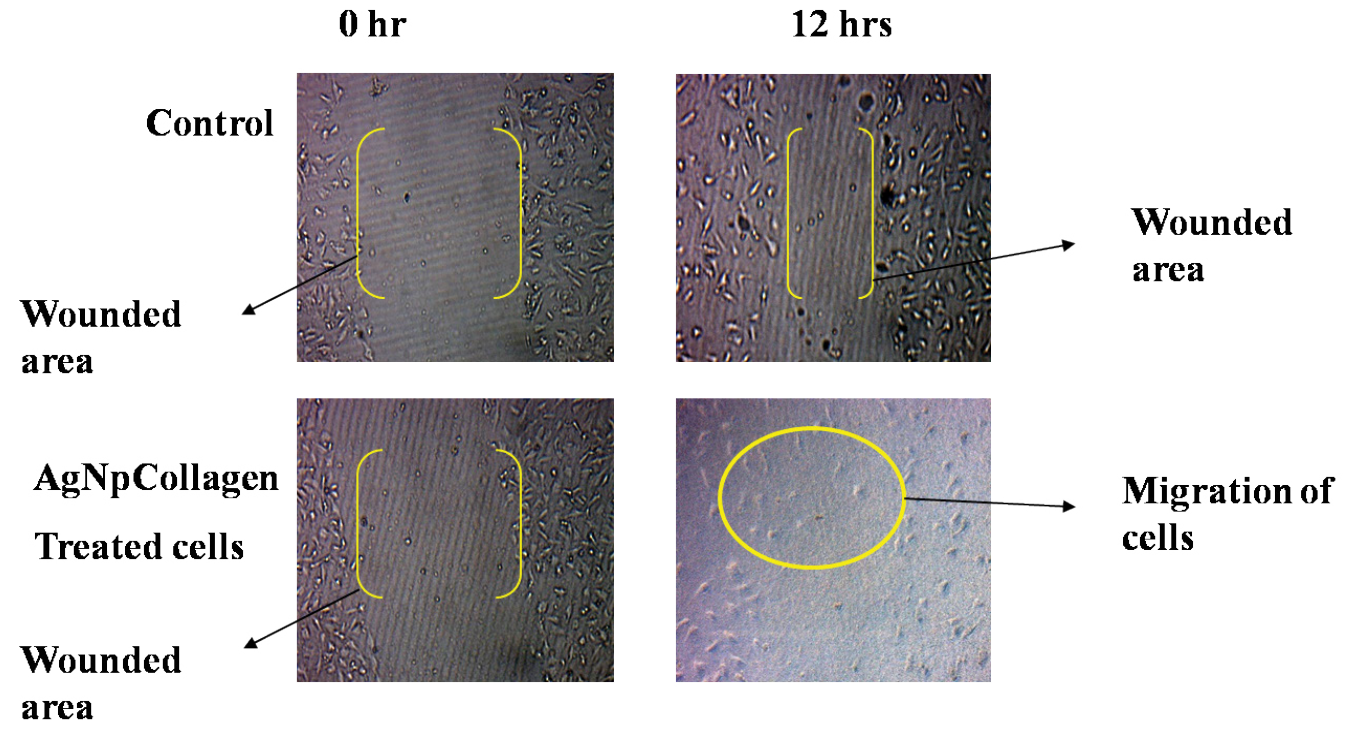

Figure 7: AgNps blended nanocollagen wound healing assay.

literature (Figure S4). Silver nanoparticles perfectly encapsulated by the collagen fibers at nanoscale. Figure S5 at supplementary information shows various SEM micrographs on collagen fibres. Figure $\mathrm{S} 6$ and Figure S7 shows various micrographs on silver nanoparticles and their impregenation with collagen fibres. Figure S3 at supplementary information shows the average diameter of silver nanoparticles evaluated via DLS is evaluated to be $274 \mathrm{~nm}$.

\section{Cytotoxicity assay}

Percentage of Cell viability against concentration of nanocollagen stabilized silver nanoparticles were plotted as a graph. Figure 6 showed that at $100 \mathrm{ng} / \mathrm{ml}$ cell viability of cells seems to have higher cell viability and this concentration was used for preclinical and clinical investigation. It was observed that higher cytotoxicity for silver nanoparticles was nearly 1000, 500, $250 \mu \mathrm{g} /$ $\mathrm{ml}$ and lower cytotoxicity was $3.90 \mu \mathrm{g} / \mathrm{ml}$. Cytotoxicity effect of collagen based silver nanoparticles on EA.hy926 was studied from higher to lower concentrations. From this study, it was concluded that at higher concentration, silver nanoparticles exhibit higher cytotoxicity but in lower concentration exhibit less effect and this could be effectively used for wound healing activity assay. It was shown in Figure 7 and this scaffold increased the cell migration in the wounded area.

Cytotoxic activity of nanocollagen stabilized with silver nanoparticles and it was tested using method of MTT assay. Percentage of Cell viability against concentration of nanocollagen stabilized silver nanoparticles was plotted as a graph. The graph showed that at $100 \mathrm{ng} / \mathrm{ml}$ cell viability of cells seems to have higher cell viability and this concentration was used for 
further study. Higher cytotoxicity was observed for silver nanoparticles nearly 1000,500, $250 \mu \mathrm{g} / \mathrm{ml}$ and lower cytotoxicity was $3.90 \mu \mathrm{g} / \mathrm{ml}$. Same pattern of results were obtained in the present study shown in Figure 6 and Figure 7. Cytotoxicity effect of nanocollagen based silver nanoparticles was studied on EA.hy926 from higher to lower concentration.

\section{Conclusion}

Silver nanoparticles higher concentration exhibit cytotoxicity when related to lower concentration showing less cytotoxicity. This silver nanoparticles effectively healing infected wounds. $100 \mathrm{ng} / \mathrm{ml}$ silver nanoparticles in nanocollagen been used for the wound healing studies on EA.hy926 cells. This standardized concentration effectively performs cell migration in the EA.hy926 cells, thereby stimulating the wound healing.. Hence nanocollagen stabilized silver nanoparticles can be used for wound healing applications. Also, these silver nanoparticles synthesized from the stem extract of Gymnema, posses great medicinal potential, so it can be used for treatment of both infected and diabetic ulcer wound healing.

\section{References}

1. Chattopadhyay S, RT Raines (2014) Collagen-based biomaterials for wound healing. Biopolymers 101: 821-833.

2. Cen L, Liu W, Cui L, Zhang W, Cao Y (2008) Collagen tissue engineering: Development of novel biomaterials and applications. Pediatr Res 63: 492-496.

3. Kumar MS, Kirubanandan S, Sripriya R, Sehgal PK (2010) Triphala incorporated collagen sponge - a smart biomaterial for infected dermal wound healing. J Surg Res 158: 162170.

4. Kim JS, Kuk E, Yu KN, Kim JH, Park SJ, et al. (2007) Antimicrobial effects of silver nanoparticles. Nanomedicine 3: 95-101.

5. Rai M, Yadav A, Gade A (2009) Silver nanoparticles as a new generation of antimicrobials. Biotechnol Adv 27: 76-83.

6. Sharma VK, Yngard RA, Lin Y (2009) Silver nanoparticles: Green synthesis and their antimicrobial activities. Adv Colloid Interface Sci 145: 83-96.
7. Raveendran P, Fu J, Wallen SL (2003) Completely "green" synthesis and stabilization of metal nanoparticles. J Am Chem Soc 125: 13940-13941.

8. Giuffrida S, Ventimiglia G, Sortino S (2009) Straightforward green synthesis of "naked" aqueous silver nanoparticles. Chem Commun 4055-4057.

9. Kulkarni N, Muddapur U (2014) Biosynthesis of metal nanoparticles: A review. Journal of Nanotechnology 2014: 8.

10. Yijun F, Qinyi H, Aoushuang L, Miaoyu W, Aoxue L (2015) Characterization and antihyperglycimic activity of a polysaccharide from Dioscorea opposita Thunb roots. Int J Mol Sci 16: 6391-6401.

11. Mohamed SA, Mohamed SS, Aziza AE, Mosaad AA (2014) Antioxidant and antibacterial activity of silver nanoparticles biosynthesized using Chenopodium murale leaf extract, Journal of Saudi Chemical Society 18: 356-363.

12. Nikalji CG, Zimare SB, Malpathak NP (2012) A comparative pharmacognostic study on the leaf, stem and root components of Gymnema sylvestre (Retz) R. Br. ex. Sm. Proceedings of the National Academy of Sciences, India Section B: Biological Sciences, 83: 125-134.

13. Sangeetha S, Rastogi A, Arunachalam S (2014) Phytochemical testing, antioxidant activity, HPTLC and FTIR analysis of antidiabetic plants Nigella sativa, Eugenia jambolana, Andrographis paniculata and Gymnema sylvestre. Reseach Journal of Biotechnology 9: 65-72.

14. Saranyadevi K, Subha V, Ravindran RSE, Renganathan S (2014) Green synthesis and characterization of silver nanoparticle using leaf extract of Capparis zeylanica. Asian Journal of Pharmaceutical and Clinical Research 7: 44-48.

15. Vigneshwaran $\mathrm{N}$, Nachane RP, Balasubramanya $\mathrm{RH}$, Varadarajan PV (2006) A novel one-pot 'green' synthesis of stable silver nanoparticles using soluble starch. Carbohydr Res 341: 2012-2018.

16. Subha V, Ravindran RSE, Sruthi $P$, Renganathan $S$ (2015) An ecofriendly approach for synthesis of silver nanoparticles using ipomoea Pes-caprae root extract and their antimicrobial properties. Asian Journal Pharmaceutical and Clinical Research 8: 103-106.

17. You C, Li Q, Wang X, Wu P, Ho JK, et al. (2017) Silver nanoparticle loaded collagen/chitosan scaffolds promote wound healing via regulating fibroblast migration and macrophage activation. Sci Rep 7: 10489. 